in the vascular intima. Another possible mechanism might be increased susceptibility of this compartment to matrix degradation, providing a favoured infiltrative route. Interestingly, the tumour we report also showed pronounced neurotropism; there may be a functional connection here, but as neurotropism is commonly seen on its own, there can hardly be just one mechanism operating to produce both infiltrative patterns. Stromal desmoplasia and pronounced elongation of melanocytes were absent in our case; therefore, it does not seem to belong to either of the specific subtypes, desmoplastic malignant melanoma or its neurotropic variant. ${ }^{45}$

1 Colby TV, Carrington CB. Pulmonary lymphomas simulating lymphomatoid granulomatosis. Am ₹ Surg Pathol 1982;6:19-32.

2 Katzenstein A, Carrington CB, Liebow AA. Lymphomatoid granulomatosis: a clinico-pathologic study of 152 cases. Cancer 1979;43:360-73.

3 Moreno A, Espanol I, Ramogosa V. Angiotropic malignant melanoma. Report of two cases. $\mathcal{F}$ Cutan Pathol nant me:3250ma.

4 Bruijn JA, Mihm MC, Barnhill RL. Desmoplastic melanoma. Histopathology 1992;20:197-205.

5 Mack EE, Gomez EC. Neurotropic melanoma. A case report and review of the literature. $\mathcal{f}$ Neuro-oncol 1992; 13:165-71.

\title{
Signet-ring cell lymphoma of bone marrow
}

\author{
D C Talbot, J H Davies, K A Maclennan, I E Smith
}

\begin{abstract}
A case of signet-ring cell lymphoma affecting bone marrow is reported. The tumour presented as multiple lytic lesions in the lumbosacral spine. A bone biopsy specimen showed the typical appearances of signet-ring cell lymphoma, and the cells stained positively with antiserum to CD20, though neither immunoglobulin light or heavy chains could be shown within the vacuoles. The patient subsequently responded to chemotherapy.
\end{abstract}

( Clin Pathol 1994;47:184-186)

Signet-ring lymphomas are a rare form of non-Hodgkin's lymphoma first described by Kim et al in 1978. ${ }^{1}$ They have a characteristic morphological appearance as a result of large vacuolated or eosinophilic inclusions which displace the nucleus to the periphery. Signetring lymphomas have been described in lymph nodes and in a variety of other organs including the orbit, ${ }^{2}$ skin $^{3}$ central nervous system, ${ }^{4}$ tonsils, ${ }^{5}$ thyroid, ${ }^{6}$ salivary gland ${ }^{7}$ and stomach. ${ }^{8}$ We report here the first case (as far as is known) of signet-ring cell lymphoma affecting bone marrow.

\section{Case report}

A 56 year old woman was referred for a second opinion regarding the further investigation and management of multiple lytic lesions of the lumbosacral spine. She had initially presented in Portugal 10 months earlier with a history of back pain which was treated with simple analgesia and physiotherapy. Her symptoms deteriorated, and three months later plain radiography showed a lytic lesion in the body of $\mathrm{Ll}$ causing partial collapse. A computed tomogram of the lumbosacral spine confirmed lytic lesions in L1, L5, and S1. The patient underwent surgical stabilisation and insertion of Harrington rods, with sub-laminary wires from D10 to $\mathrm{L} 2$, with a bone graft from the left ilium. A bone biopsy specimen at this time had shown necrotic tissue only, and she was given quadruple antituberculous chemotherapy on an empirical basis.

At the time of referral, three months after the operation, she had considerable back pain, limiting her mobility. The only abnormal physical sign of note was reduced dorsiflexion of the left halux. Her erythrocyte sedimentation rate was $7 /$ first hour and a full peripheral blood count was normal, including a differential white cell count. Liver function tests, including alkaline phosphatase and serum calcium were normal, as was serum electrophoresis. Urinary Bence-Jones proteins were absent. Plain radiography and computed tomography confirmed extensive lytic deposits in the lumbo-sacral spine. A bone marrow aspirate and trephine biopsy specimen were not diagnostic and so a computed tomography guided biopsy of the lytic deposits was performed. A computed tomogram of the chest as part of the staging procedure showed multiple small opacities within both lung fields, but these were not biopsied. Treatment with the combination of cyclophosphamide, doxorubinin, vincristine and prednisolone resulted in symptomatic benefit and an objective partial response.

\section{Methods}

As a result of the computed tomography guided biopsy, several pieces of bone were received, the largest about $2 \mathrm{~cm}$ in diameter. 
Figure 1 Low power view showing erosion and and complete replacement of bone marrow by malignant lymphoma. necrosis of bone trabeculae

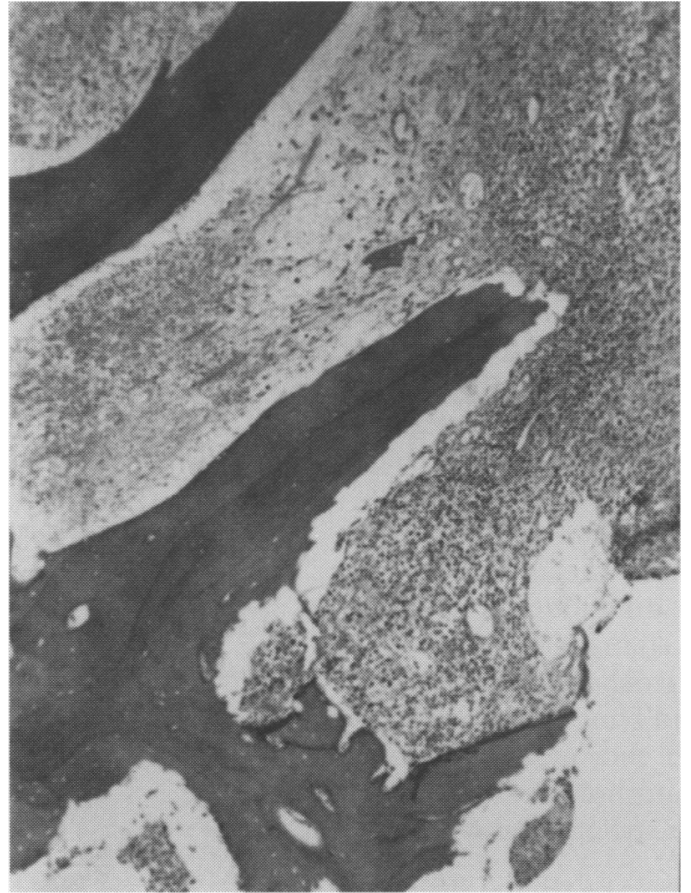

Figure 2 High power view showing displacement of the hyperchromatic nuclei to the periphery of the cell resulting in a "signet-ring" morphology.

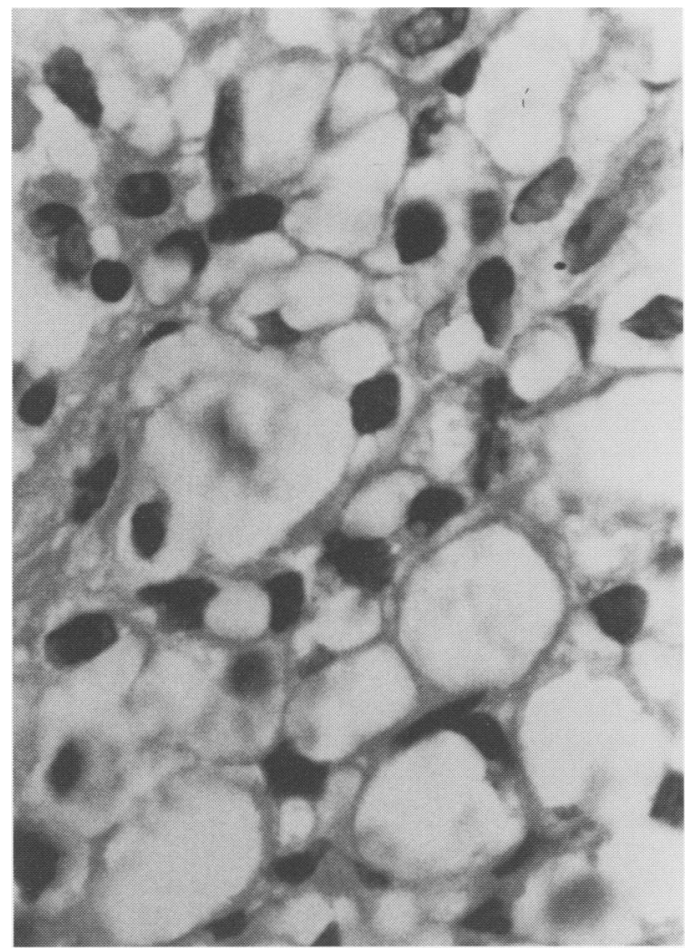

The tissue was fixed in $10 \%$ neutral buffered formalin and subsequently decalcified in $30 \%$ formic acid. The material was embedded in paraffin wax and $5 \mu \mathrm{m}$ sections were cut and stained with haematoxylin and eosin, periodic acid Schiff with and without prior diastase digestion, and with mucicarmine.

Immunohistochemical staining was performed using the streptavidin alkaline phosphatase method. Polyclonal antisera used included antisera to IgG, IgM, $\kappa$ and $\lambda$ light chains and CD3. Monoclonal antisera to CD20 (L26) and CD45RO (UCHL1) were also used. All antisera were obtained from Dako.

\section{Histological findings}

The sections consisted of largely necrotic bone and bone marrow (fig 1). Diffuse infiltration of bone and bone marrow by sheets of large cells occurred, most of which had the cytoplasm apparently replaced by a large, central vacuole. The latter produced a displacement of the hyperchromatic nuclei to the periphery of the cell, resulting in a "signet-ring" morphology. Nucleoli were not prominent. Mitoses were frequent as well as areas of necrosis (fig 2).

Admixed with the signet-ring cells were pleomorphic large cells with central nuceli, one to three indistinct nucleoli, and a smaller amount of eosinophilic cytoplasm. These too showed frequent mitoses. Moderate numbers of small cleaved cells and small lymphocytes were also present. A nodular growth pattern was not seen. Using the Working Formulation of the National Cancer Institute, USA, the infiltrate was classified as malignant lymphoma, intermediate grade, diffuse large cell type (Kiel classification: high grade centroblastic). ${ }^{9}$

No staining was seen with the PAS stains or with mucicarmine. The large cells, both those with central vacuoles and the smaller number of non-vacuolated cells, and the small cleaved cells, stained strongly positive with antiserum to CD20. Positive staining for the $\mathrm{T}$ cell markers, CD45RO, and CD3, was seen in the accompanying small lymphocytes. No relevant staining with antiserum $\kappa$ and $\lambda$ light chains was seen. Some positive staining for IgG was shown within the cytoplasm of a few of the pleomorphic large cells, but no immunoglobulin staining was seen within the vacuoles.

\section{Discussion}

Signet-ring cell lymphoma is a rare morphological variant of non-Hodgkin's lymphoma first reported by $\mathrm{Kim} e t \mathrm{ll}^{1}$ in 1978. Initial reports suggested that such features were restricted to B cell malignancies, notably follicle centre cell derived lymphomas, ${ }^{1}{ }^{10}{ }^{11}$ but subsequent publications on $\mathrm{T}$ cell signet-ring cell lymphomas have appeared. ${ }^{12-13}$

The term has been used to cover two main morphological variants. The first, and more common, consists of cells with peripherally located nuclei and a vacuolated cytoplasm. Some, but not all of these, have been shown to contain IgG. ${ }^{1}$ In the second variant the nuclear dispacement is the result of abundant eosinophilic cytoplasm, producing a Russell body-like appearance. These cases have shown positive staining for IgM. ${ }^{1}$ The nature of the vacuoles is uncertain, and these were initially, in B cell lymphomas, thought to represent immunoglobulin accumulation. However, several ultrastructural studies have shown microvesicular and membranous structures in the vacuoles. Grogan et al ${ }^{13}$ have suggested that the vacuolated appearance might derive from aberrant membrane recycling with internalisation of surface membrane antigens. Such a theory is applicable to 
both $B$ and $T$ cell lymphomas, and helps to explain cases, such as ours, in which immunoglobulin is not demonstrable within the vacuoles.

To our knowledge this is the first case of signet-ring cell lymphoma to affect bone marrow. The patient presented with bone lesions, and there was no clinically apparent lymphadenopathy. There seems to be no difference in clinical behaviour between signet-ring cell lymphomas and their morphologically conventional counterparts. The main interest lies in the histological appearance. Signet-ring cells are seen in tumours as diverse as adenocarcinoma (diffuse gastric adenocarcinomas), liposarcoma, and malignant melanoma ${ }^{14}$ and can cause diagnostic difficulties. Special stains (such as mucin stains and MassonFontana) and immunohistochemistry (including cytokeratin, S100, and lymphoid markers) will be required, though thorough sampling may reveal areas with morphological features more characteristic of the specific tumour.

$1 \mathrm{Kim}$ H, Dorfman RF, Rappaport H. Signet ring cell lymphoma: a rare morphological and functional expression of nodular (follicular) lymphoma. Am $\ngtr$ Surg Pathol 1978;2:119-32.
2 Dolman PJ, Rootman J, Quenville NF. Signet-ring cell lymphoma in the orbit: a case report and review. Can $\mathcal{F}$ Ophthamol 1986;21:242-5.

3 Hanna W, Kahn HJ, From L. Signet ring lymphoma of the skin: Ultrastructural and immunohistochemical feathe skin: Ultrastructural and immunohistoc

4 Pappas CTE, Johnson PC, Sonntag VKH. Signet-ring cell lymphoma of the central nervous system case report. $f$ Neurosurg 1988;69:789-92

5 Dardick I, Srinivasan R, Al-Jabi M. Signet-ring cell variant of large cell lymphoma. Ultrastruct Pathol 1983;5:195-200.

6 Allevato PA, Kini SR, Rebuck JW, Miller JM, Hamburger II. Signet-ring cell lymphoma of the thyroid: a case report. Hum Pathol 1985;16:1066-8.

7 Stramignoni A, Palestro G, Coda R, et al. Signet ring cell lymphoma in salivary gland. An immunohistochemical and ultrastructural study. Appl Pathol 1984;2:76-84.

8 Tungekar MF. Gastric signet-ring cell lymphoma with alpha heavy chains. Histopathology 1986;10:725-33.

9 Stansfeld AG, Diebold J, Noel T, et al. Updated Kiel classification for lymphomas. Lancet 1988;i:292-3.

10 Van den Tweel JG, Taylor CR, Parker JW, Lukes RJ. Immunoglobulin inclusions in non-Hodgkin's lymphomas. Am $\mathcal{f}$ Clin Pathol 1978;69:306-13.

11 Harris M, Eyden B, Read G. Signet ring cell lymphoma: a rare variant of follicular lymphoma. I Clin Pathol 1981;34:884-91.

12 Weiss LM, Wood GS, Dorfman RF. T-cell signet-ring cell lymphoma: A histologic, ultrastructural, and immunohistochemical study of two cases. Am f Surg Pathol 985;9:273-80.

13 Grogan TM, Payne CM, Richter LC, Rangel CS. Signetring cell lymphoma of T-cell origin: An immunocytochemical and ultrastructural study relating giant vacuole formation to cytoplasmic sequestration of surface membrane. Am ₹ Surg Pathol 1985;9:684-92.

14 Sheibani K, Baltifora H. Signet-ring cell melanoma: a rare morphological variant of malignant melanoma. $\mathrm{Am} \mathrm{f}$ Surg Pathol 1988;12:28-34. 